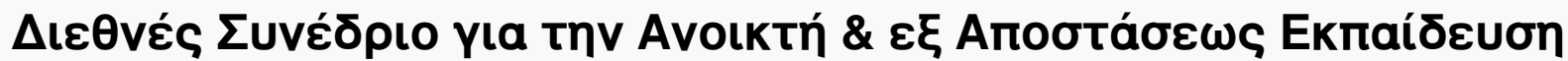

Tóp. 9, Ap. 6B (2017)

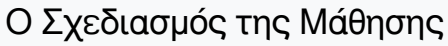

Tónos 6, Mépos B

\section{Практіка́}

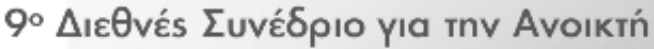

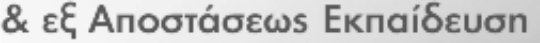

A Ańva, 23 - 26 Noe $\mu$ B píou 2017

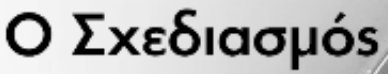
ins MáӨnons

Enıนédeıa

Avióvns Aıvapákns

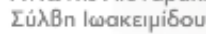

Mapia Niápn

「кé̀n Mavoúoou

Tóvia Xaproqú

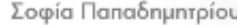

Avva Anoorodíbou

ISBN 978.618.5335-01.4

ISBN SET 978-618-82258-5-5

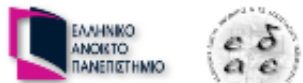

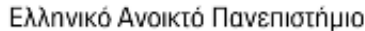

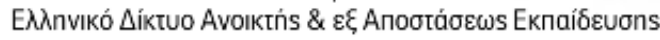

Implementation and optimisation of an e-Learning Community for Language Teachers

RANIA VASILEIOS VOSKAKI, THOMAIS VASILEIOS ROUSOULIOTIS

doi: $10.12681 /$ icodl.1140 


\title{
Implementation and optimisation of an e-Learning Community for Language Teachers
}

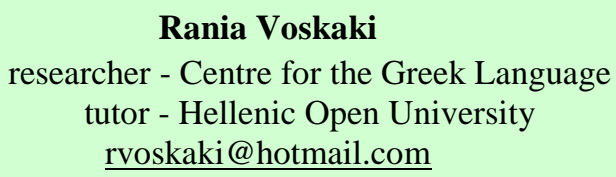

Rania Voskaki

researcher - Centre for the Greek Language tutor - Hellenic Open University rvoskaki@hotmail.com

\author{
Thomais Rousoulioti \\ researcher - Centre for the Greek Language \\ tutor - Hellenic Open University \\ rousouliotith@yahoo.gr
}

\begin{abstract}
This paper aims to present the development and implementation of the e-learning community Routes in Teaching Modern Greek as a Second/Foreign Language, from 2015 to the present. The above programme constitutes a professional training programme addressed to current or future teachers of Modern Greek as a second/foreign language, initiated in 2007 (Ypsilantis, 2008) and constantly reviewed and enriched up to 2015 (Kokkinidou et al., 2014). The programme is based on (a) the theoretical principles of distance learning (Lionarakis, 2001) related with adult education (Kokkos, 2005), (b) experimental knowledge (20072015) and (c) the statutory role of the Centre for the Greek Language, as the topic concerns teaching Modern Greek in Greece and abroad. More specifically, we focus on the optimisation process undertaken in the latest version of Routes in Teaching Modern Greek as a Second/Foreign Language.
\end{abstract}

Keywords: distance training programme, e-learning community, adult education, teaching Modern Greek as L2, professional training programme, video conference, collaborative activities, interaction

\section{Introduction}

This paper reports on Routes in Teaching Modern Greek as a Second/Foreign Language (henceforth Routes), an e-learning programme conducted by the Centre for the Greek Language. Routes constitute a professional training programme conceived in order to empower teachers' ability in teaching Modern Greek as a second/foreign language (L2) ${ }^{1}$. The implementation periods of the programme are three: (a) the first version was delivered from 2007 to 2011 in four training cycles (Ypsilantis, 2008), (b) the second, updated version, from 2011 to 2015, in four training cycles (Kokkinidou et al., 2014), and (c) the third and latest version, from 2015 to the present, in two training cycles. Currently, the ongoing training cycle of the programme is the tenth, while the next one is scheduled to start in October 2017. By the term "training cycle", we define a ten-month course delivered once every academic year.

The aim of the present article is to describe the third and latest version of Routes, as it has been updated since 2015. Initially, the theoretical background is set forth, while we focus on the optimisation process undertaken. More specifically, we present the current structure of the e-learning community, the redesigning of the modules' content and the updates made in the framework of the technology 
implementation process. The experimental knowledge gained from the first eight training cycles and the evolution of technology form the basis for the modifications made.

\section{Theoretical background}

Routes adopt the principles of distance learning as defined by Lionarakis (2001: 185) to be "the kind of education that teaches and empowers the learner how to learn by themselves and how to operate autonomously towards a heuristic course of self-learning and knowledge". Under this condition, the development of the training material of the programme was based on the principles of distance learning and the guidelines of Knowles theory of Andragogy which refers to any form of adult education.

According to Knowles in Kokkos (2005: 48-49), the theory of Andragogy is based on six basic principles:

1. Adult learners need to know why they need to learn something before they are actively involved in the learning process.

2. Adult learners need to define themselves, i.e. to make their own decisions about their lives, and, at the same time, have the need for others to deal with them.

3. Adult learners have accumulated multiple and complex experiences that differentiate them from children, as these experiences are a source of learning for themselves.

4. Adult learners want to acquire knowledge that will help them deal with some of the situations they experience.

5. Adult learners want to acquire specific knowledge rather than come into contact with abstract academic concepts.

6. Adult learners have strong internal motivation for learning.

The success of distance learning programmes such as Routes depends to a large extent on the trainee's ability to direct and manage his/her learning process, both by setting appropriate goals and by developing and adopting useful strategies to achieve them. As the trainee's autonomy characterises the environment of distance learning, it is self-evident that self-regulated learning is an important and critical success factor.

This necessity arises from the extremely high degree of autonomy of trainees in distance learning, from the physical absence of the instructor and/or from the lack of strong interaction between the parties involved and from the sense of isolation that the trainees probably feel. In order to overcome the above issues in Routes, we give trainees the possibility to self-manage the educational material and make creative use of the e-learning system possibilities as presented below.

\section{The structure of the programme}

The updated Routes consist of eight (8) instead of six (6) -as in the first version of the programme ${ }^{2}$ - obligatory modules, as they have been set out in the Official Government Gazette. In the third version of the programme, all modules have been reviewed and rewritten, in accordance with the findings of contemporary scientific research. The scientific work is mainly carried out by the course coordinator in cooperation with the instructors of each module, under the supervision of Professor I. N. Kazazis ${ }^{3}$.

The aforementioned modules covering all thematic areas of interest for teachers of Modern Greek as L2 are: 
1. Syllabus Design, Classroom Management and Learning Strategies

2. Teaching Grammar, Vocabulary and Pronunciation

3. Teaching Languages to Young Learners

4. Language Performance Assessment

5. Computer Assisted Language Learning

6. Aspects of Language

7. Bilingualism: Language and Thought in the Bilingual Speaker

8. When Cultures Converse at School: Intercultural Education Issues

To each module a coordinator, three instructors and up to approximately 150 trainees are assigned. The teaching team (coordinator and instructors) consists of researchers with expertise in the thematic field of the module, as well as in distance learning.

As far as trainees' experience and knowledge in teaching Modern Greek as L2 is concerned, two groups are observed: (a) current teachers of Modern Greek as L2, without any official special certification or a relevant Master's degree and (b) future teachers, with no experience in teaching Greek as L2. During the tenmonth period of each training cycle, the group of trainees with experiential knowledge in the field interacts with the second group within the framework of peer learning. The aim is, through interaction between both groups and the instructors, to exchange and adopt the best practices in teaching Modern Greek as L2.

\subsection{Redesigning the modules' structure and content}

According to Lionarakis (2001), the role of the educational material in distance learning is to:

- support the trainee's work, to activate, train and teach him/her;

- make the trainee able to learn independently, autonomously and creatively;

- help the learner discover knowledge and information through specific activities and through self-learning processes.

These principles have been applied throughout the development of the reviewed training material. Each module consists of three to four different units, covering all major issues, relevant to the module's thematic area. Every unit is organised in a way that makes it readable and easy to understand, so as to attract trainees' interest. The structure of the module is designed taking into account the three features of self-regulated learning (Zimmermann, 1990: 6-7): (a) the use of selfregulated learning strategies (b) the responsiveness to self-oriented feedback about learning effectiveness, and (c) the interdependent motivational processes. Trainees can manage the material of the module, according to their educational needs, in a non-linear way, while applying self-assessment questions.

Thus, the material of each unit is divided into two categories: (a) the principal material, and b) the supplementary material.

a) The principal material

At the beginning of each unit, trainees have the chance to watch a video lecture, describing the content and the key issues of the unit. Afterwards, they have access to a powerpoint presentation in which they come for the first time in contact with the teaching material of the unit. All powerpoint presentations are organised in a way that ensures the clarity of the teaching material that follows and illustrate the main points of the unit. Right after the powerpoint presentation, trainees can either read online or download a pdf document, where all the key 
issues presented in the above mentioned powerpoint presentation are analysed. The basic structure of a unit is depicted in Table 1 below.

\begin{tabular}{ll}
\hline $\mathbf{1 .}$ & Contents \\
\hline $\mathbf{2 .}$ & Unit description \\
$\mathbf{3 .}$ & Aims and objectives \\
$\mathbf{4 .}$ & Study organisation \\
$\mathbf{5 .}$ & Study duration \\
\hline $\mathbf{6 .}$ & Main body of the unit \\
\hline $\mathbf{7 .}$ & Self-assessment questions \\
\hline $\mathbf{8 .}$ & Summary \\
\hline $\mathbf{9 .}$ & Appendix \\
\hline
\end{tabular}

Table 1. The basic structure of the unit

After the Contents, the trainee can find under the heading Unit description the general description of the main points of the section that follows. Subsequently, an outline of the Aims and objectives of the unit is briefly presented. Special reference is made to what the trainee should know when completing the study of the module in the form of "need to know statements".

Instructions ensue about the Study organisation of the unit. These instructions include information on how trainees can deal with the teaching material and manage all the information given in it step by step. These instructions are in the form of advice and are not intended to impose a specific way and pace of study on trainees. Besides, in distance learning, self-regulated learning is expected (Armakolas, Panagiotakopoulos, Massara, 2015: 105, Mikroyannidis et al., 2014: 148).

Shortly before the study material of the unit, reference is made to the time required for studying the teaching material of the unit under Study duration, both with regard to conventional and electronic resources, as well as the consolidation and self-assessment activities that are included in the unit. The self-assessment activities are usually placed at the beginning of each unit.

Then, as mentioned under heading 6 in Table 1 above, the Main body of the unit follows, consisting of chapters and sections. In this part, all study material of the unit is scientifically developed and documented. All study material is written in a way that is reader-friendly. Every unit is enriched with tables, bar graphs and pictures that help the reader understand all the information given easily.

Both at the beginning and at the end of the unit, there are Self-assessment questions. Self-assessment questions help the learner initially reflect on key issues regarding Modern Greek as L2 presented in the unit. For that reason, trainees come across them just before the development of the Main body of the unit. The same self-assessment questions are also found at the end of the development of the Main body of the unit. At this point, however, after having studied the educational material, trainees should be able to answer them.

Additionally, various points in the text refer to web pages, to which the corresponding hyperlinks have been made. In this way, trainees are able to find additional information or explanations regarding the material under study. They are also able to expand their knowledge or to update that existing with new scientific data.

Finally, at the end of the aforementioned pdf document, trainees have the chance to read the Summary of the unit, thus having the opportunity to summarise what 
they have already read. The extended pdf file closes with an Appendix, including a key to the consolidation activities. In this way, the architecture of the unit facilitates trainees to cross-check the answers they have given.

b) The supplementary material

The second part of each module consists of the supplementary material. The supplementary material consists mostly of articles that provide learners with an in-depth understanding of the training material of the module. In a number of cases, free-access websites have been included in the supplementary material. In addition, the supplementary material has been enriched with glossaries at the end of each training module. These glossaries present and illustrate the specific terminology used in each module. It is clear that trainees can manage the training material by themselves, as its development is non-linear, and study it by focusing on different points at a time.

\subsection{Assessment of trainees}

In order to reduce trainees' potential isolation, as well as in the context of promoting future collaboration between them as teachers of Modern Greek as L2, collaboration assignments are provided in some modules. Interaction is promoted through assignments that have to be undertaken in collaboration, among two or three trainees (Roberts \& Pruitt, 2009: 5). Moreover, an electronic repository is available, containing assignments from previous training cycles. Teaching teams (coordinator and instructors of each module) select assignments delivered by trainees of previous cycles, so as to help current trainees while working on their own assignment per module. It should be noted that the evaluation criteria of each assignment are announced to trainees from the beginning of the module and that they receive feedback from the instructors after completing the module. A successful completion of the training programme requires eight assignments which have been evaluated as successful. In case of failure in an assignment (lower than 60\%), trainees can resubmit their corrected assignment, taking into account the remarks made by the instructors in the feedback report.

\subsection{Implementation of technology}

Since their first launch in 2007, Routes have been based on constant advances provided by Information and Communication Technology (ICT) applications. Through ICT applications, large-scale electronic material and information can be shared and/or distributed at high speed across distances that may span the globe. Similarly, flexibility between synchronous and asynchronous communication tools contributes to peer contact between members (both instructors and trainees) in distance learning (Belanger and Jordan, 2000, Dix et al., 2004).

From the start, our application tool of choice, among the existing Learning Management Systems (LMS) was Moodle ${ }^{4}$. Due to flexibility to regular system updates, open source use possibility, $\mathrm{SCORM}^{5}$ standards offered, and its userfriendly interface, Moodle has been proved to be the adequate tool in terms of effectiveness and efficiency. More precisely, Moodle met our requirements as far as course designing is concerned in terms of: (a) module division, (b) unit subdivision, (c) sharing teaching material, (d) assignment submission by trainees, (e) assignment feedback reports by instructors, (f) uploading multimedia teaching materials (instructors' video lectures), and (g) asynchronous discussion forums. It should be mentioned that each module has its own discussion forum that largely takes the place of the conventional in-class environment. Moreover, an extra 
discussion forum is provided in the initial web page for general announcements (e.g. informing about relevant events, or new teaching material, grading notifications, deadlines, etc.).

Asynchronous communication between Routes' members (instructors and trainees) is also achieved by personal e-mails through the Moodle platform and/or the conventional mailbox. E-mails mainly cater for more private discussions that need to be made between a trainee and an instructor, or between trainees in the framework of a collaborative assignment on which they need to elaborate. Alternatively, in case of real time communication needs, Skype is used between two and/or three members through Skype conferences.

As far as synchronous communication is concerned, video conferences have been integrated in the training schedule in the updated version of Routes. Within the framework of distance learning programmes, meeting tools provide real time communication via audio and video. Participants (both instructors and trainees alike) may join the video conferences from any location as long as they have sufficient bandwidth, a webcam and a microphone speaker. According to Coventry (2004), video conferencing in distance education offers: (a) social contact, (b) telepresence, (c) group coherence, (d) increased access to teachers and experts. Coventry (2004) points out that "video conferencing could lead the way for a dual approach, giving students more responsibility for their learning, working in groups, doing tasks [...] and provides an opportunity to implement them".

In each module, a video conference is organised at least several days before the assignment submission. The exact date and content of each video conference are announced in time in the discussion forum by the coordinator in charge of the module. Trainees may propose different dates, as well as supplement subjects for discussion during the announced video conference. The coordinator and the instructors of each module participate in the video conference, while participation is optional for trainees. It is preferable to have groups of a maximum of 25 participants in each video conference, as the objective of video conferences is to promote real time communication and interaction between participants during which short tasks are often assigned to them, therefore larger groups of trainees would hinder this kind of communication in practical terms. For the trainees who cannot participate, the video conference is recorded and uploaded on the initial web page of each module. When needed, a second video conference can be organised in order to include the real time participation of more trainees.

Among the existing web-based online meeting tools, we have been using, since 2015 , WebEx ${ }^{6}$. Some of the included features in WebEx have been proved to be important while using this tool in Routes, such as: (a) incorporated broadcast recorder, (b) instant messenger (useful before starting the video conference for trainees who have difficulties in checking audio settings, (c) whiteboard, (d) sharing desktop and/or e-material, (e) swapping presenter (in case of instructors in different locations, or trainees willing to present material on their desktop), (f) connectivity from any electronic device besides computers (e.g. tablets, smartphones, etc.). An overview of the development of relationships between participants in the programme, training material and electronic tools is as follows (Figure 1). 


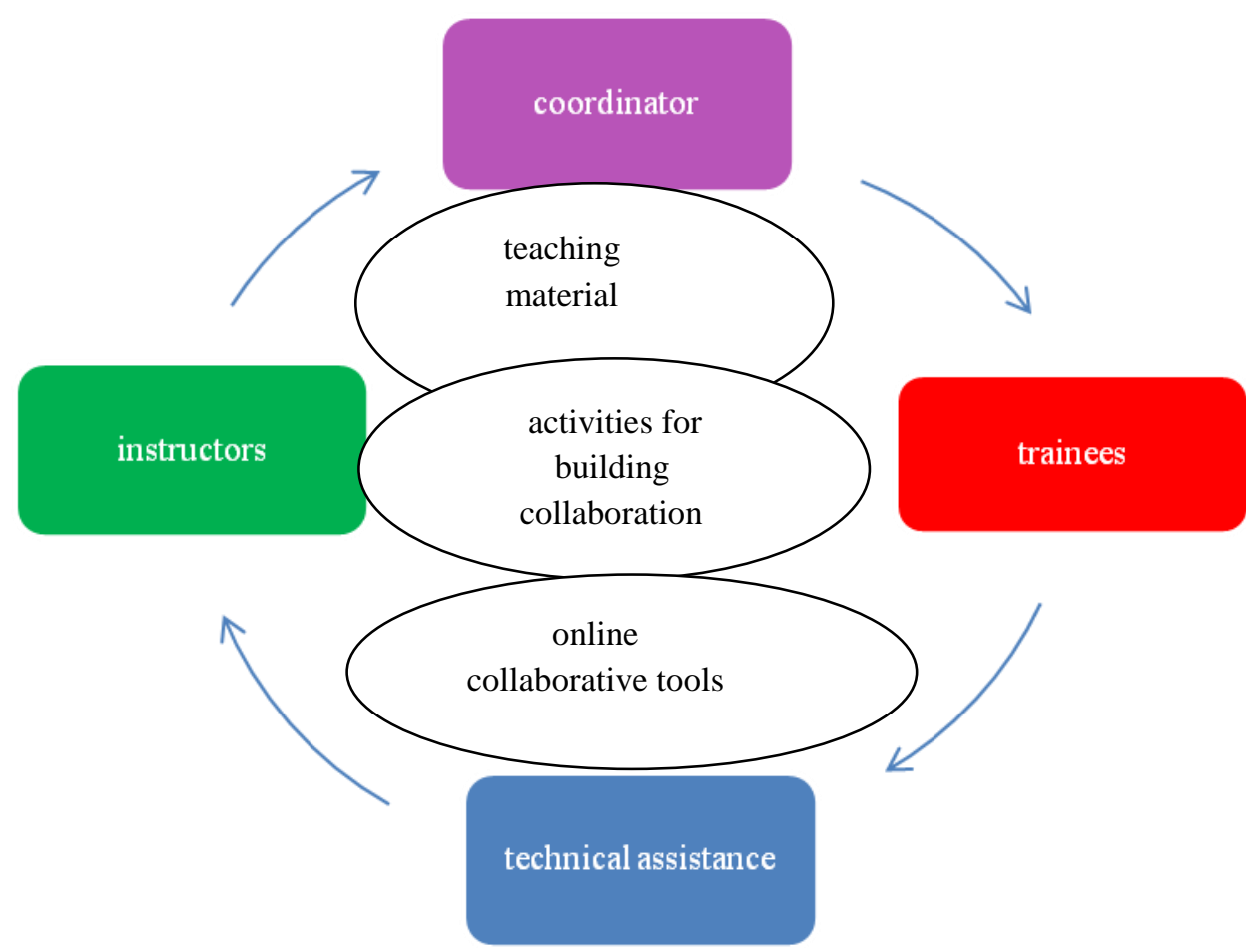

Figure 1. The relationships among the components of the programme

\section{Conclusion and further research}

In this paper, the optimisation process of the e-learning community Routes is presented, the structure of which has been reviewed and updated. More specifically, the modules' structure has been redesigned in order to include the latest scientific findings and all new scientific trends. What is more, more electronic tools have been added, so as to increase the interaction between participants (both instructors and trainees). The development of collaborative activities is considered to be a major issue in e-learning communities, not only for the effective completion of the training programme, but mainly for the maintaining of collaboration between teachers of Modern Greek as L2 worldwide. Within that scope, the future development of an e-community of practice addressed to teachers of Modern Greek as L2 who have participated in Routes is among our future plans. Furthermore, analysing the outcomes and findings arising from the trainees' evaluation feedback questionnaires is considered important. Shortly, the second training cycle of the current version will be completed, and we will be able to evaluate that data in relation to the percentage of the trainees who have successfully completed the programme. Thus, further optimisation of the distance training programme will be achieved.

\section{References}

Armakolas, S., Panagiotakopoulos, Ch. \& Massara. Chr. (2015). H $\alpha v \tau o \rho \rho v \theta \mu 1 \zeta o ́ \mu \varepsilon v \eta$

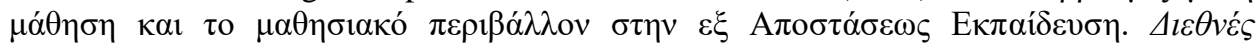

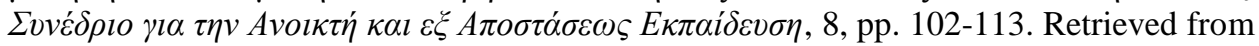
https://eproceedings.epublishing.ekt.gr/index.php/openedu/article/download/32/24 $(29 / 8 / 2017)$

Belanger, F., \& Jordan, H. D., (2000). Evaluation and implementation of distance learning Technologies, tools and techniques. USA: Idea Group Publishing. 
Coventry, L. (2004). Video Conferencing in Higher Education. Retrieved from: http://www.agocg.ac.uk/reports/mmedia/video3/contents.htm (3/9/2017)

Dix, A., Finlay, J., Adowd, G. \& Beale, R. (2004). Human - computer interaction. London: Pearson Education Limited.

Knowles, M.S. (1980). The Modern Practice of Adult Education. Chicago: Association Press.

Kokkinidou, A., Pranentsi, K. \& Rousoulioti, T. (2014). "The "Routes in teaching Modern Greek" programme: A practical example of online language teacher training". In Proceedings of the 7th International Conference of Education, Research and Innovation (ICERI 2014).Seville, Spain. ISBN: 978-84-617-2484-0, ISSN: 2340-10, pp. 4289-4294. Retrieved from https://library.iated.org/view/KOKKINIDOU2014ROU (15/4/2017)

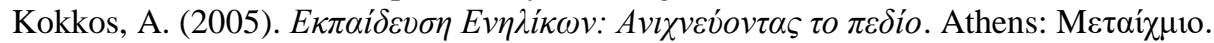

Lionarakis, A. 2008. The theory of distance education and its complexity. European Journal of Open, Distance and E-learning. Retrieved from http://www.eurodl.org/materials/contrib/2008/Lionarakis.pdf (27/8/2017)

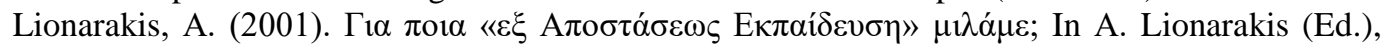

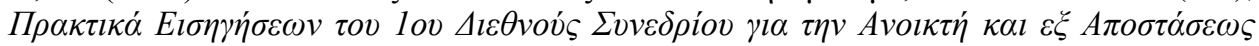

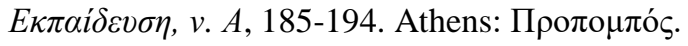

Mikroyannidis, A., Connolly T. \& Law, E. (2012). A survey into the teacher's perception of selfregulated learning. In Proceedings of 2012 IEEE 12th International Conference on Advanced Learning Technologies (ICALT), pp. 696-697.

Roberts, S. M., \& Pruitt, E. Z. (2009). Schools as professional learning communities: collaborative activities and strategies for professional development $\left(2^{\text {nd }}\right.$ ed.). Thousand Oaks, California: Corwin Press.

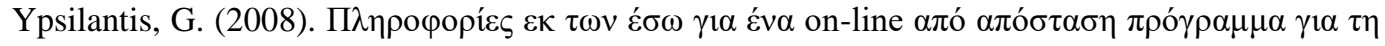

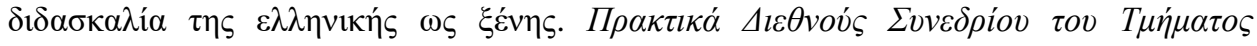

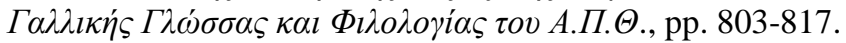

Zimmermann, B. J. (1990). Self-Regulated Learning and Academic Achievement: An Overview. Educational Psychologist, 25, 1, 3-17.

\footnotetext{
${ }^{1}$ Routes have been ratified as a professional training programme in the Official Government Gazette (No. 1430, 30/04/2012, Issue B \& No. 862, 08/04/2014, Issue B).

${ }^{2}$ Information on the first two years of the programme and the way the modules were developed at that time is provided by Ypsilantis (2008), who was the designer of the first version of Routes.

${ }^{3}$ Scientific supervision of Routes until 2010 was carried out by Professor N. Antonopoulou.

${ }^{4}$ Modular Object-Oriented Dynamic Learning Environment: https://moodle.org/.

${ }^{5}$ Sharable Content Object Reference Model.

${ }^{6}$ https://www.webex.com/.
} 